\title{
Development of in situ Ophthalmic gel of Dexamethasone Sodium Phosphate and Chloramphenicol: A Viable Alternative to Conventional Eye Drops
}

\author{
Ketan Ranch ${ }^{1 *}$, Hetal Patel ${ }^{1}$, Laxman Chavda ${ }^{1}$, Akshay Koli ${ }^{1}$, Furqan Maulvi ${ }^{1}$, Rajesh K. Parikh ${ }^{2}$ \\ ${ }^{1}$ Department of Pharmaceutics, Maliba Pharmacy College, Uka Tarsadia University, Surat, Gujarat, India - 394350 \\ ${ }^{2} \mathrm{~L}$ M College of Pharmacy, Ahmedabad, Gujarat, India.
}

\begin{tabular}{|c|c|}
\hline ARTICLE INFO & ABSTRACT \\
\hline $\begin{array}{l}\text { Article history: } \\
\text { Received on: } 19 / 07 / 2016 \\
\text { Accepted on: } 22 / 08 / 2016 \\
\text { Available online: } 30 / 03 / 2017\end{array}$ & $\begin{array}{l}\text { Context: Poor bioavailability }(<10 \%) \text { of drugs from conventional eye drops is mainly due to the various } \\
\text { precorneal loss factors which include rapid tear turnover, systemic drug absorption through naso-lachrymal duct, } \\
\text { transient residence time of the drug solution in the cul-de-sac and the relative impermeability of the drugs to } \\
\text { corneal epithelial membrane. }\end{array}$ \\
\hline $\begin{array}{l}\text { Key words: } \\
\text { Full factorial design, } \\
\text { response surface } \\
\text { methodology, gellan gum, } \\
\text { dexamethasone sodium } \\
\text { phosphate, chloramphenicol. }\end{array}$ & $\begin{array}{l}\text { Objective: The objective of present work was to develop sustain release in situ ophthalmic gel of } \\
\text { dexamethasone sodium phosphate (DXM) and chloramphenicol (CHL) using experimental design. } \\
\text { Material and methods: Gellan gum (an ion sensitive polymer) in combination with carbopol } 940 \text { ( } \mathrm{pH} \text { sensitive } \\
\text { polymer) were used as gelling agent. The developed formulations were characterized for clarity, } \mathrm{pH} \text {, in vitro } \\
\text { gelling capacity, viscosity, assay, in vitro drug release, mucoadhesive strength. Optimum formulation was } \\
\text { selected based on validated quadratic polynomial equations developed using response surface methodology. } \\
\text { Results and Discussion: The optimized formulation exhibited } 0.2 \mathrm{~N} \text { mucoadhesive strength; } 4013 \text { cps viscosity } \\
\text { at physiological condition and } 90 \% \text { release of both drugs over a period of } 10-12 \mathrm{hrs.} \\
\text { Conclusion: Mucoadhesive in situ gel for prolong ocular delivery of DXM and CHL was developed using } 3^{2} \\
\text { full-factorial experimental design. The developed stable formulation could be a viable alternative to } \\
\text { conventional eye drops for treatment of endophtalmitis. }\end{array}$ \\
\hline
\end{tabular}

\section{INTRODUCTION}

Ocular bioavailability of drugs applied topically as eyedrops is very poor. The absorption of drugs in the eye is severely limited by some protective mechanisms that ensure the proper functioning of the eye, and by other concomitant factors like, drainage of the instilled solutions, lachrymation and tear turnover, metabolism, tear evaporation, non-productive absorption/adsorption, limited corneal area and poor corneal

\footnotetext{
* Corresponding Author

Dr. Ketan M. Ranch, Maliba Pharmacy College, Uka Tarsadia University, Bardoli-Mahuva road,Dist. Surat (Gujarat), India . Contactno: +91-9925475599, Email id: ketan.ranch@utu.ac.in
}

permeability, binding by the lachrymal proteins (Gupta et al., 2010). The drainage of the administered dose via the nasolachrymal system into the nasopharynx and the gastrointestinal tract takes place when the volume of fluid in the eye exceeds the normal lachrymal volume of 7-10 $\mu \mathrm{L}$. Thus, the portion of the instilled dose (1-2 drops, corresponding to 50-100 $\mu \mathrm{L})$ that is not eliminated by spillage from the palpebral fissure is drained quickly. Therefore, the contact time of the dose with the absorbing surfaces (cornea and sclera) is reduced to a maximum of 2 min (Gupta et al., 2007). Sometimes systemic absorption of the drug drained through the nasolachrymal duct may result in some undesirable side effects (Maurice and Mishima, 1984). To overcome these problems various ophthalmic vehicles, such as suspensions, ointments, inserts and aqueous gels have been investigated to extend the ocular residence time of medications for topical application to the eye (Pal Kaur and Kanwar, 2002). 
These ocular drug delivery systems offer some improvement over a conventional liquid dosage form but because of blurred vision (e.g., ointments) or lack of patient compliance (e.g., inserts); they have not been universally accepted. The use of preformed gels still has a number of lacunas, which has limited their use in ophthalmic drug delivery. These preformed gel formulations do not allow accurate and reproducible administration of drugs and after administration these often produced blurred vision, crusting of eyelids, and lachrymation. Application of in situ gel approach offers advantages of both gels and solutions to have accurate dose administration with enhanced residence time in ocular cavity. Polymer combination approach reduces the high concentration of polymer when used alone. Combination of topical corticosteroids dexamethasone sodium phosphate and broad spectrum antibacterial agent chloramphenicol extended release ocular formulation reduces dosing frequency and thereby improving patient compliance in the ocular endophthalmitis. In-situ gel system is a new and recent approach, which combines the advantages of both gels and solution so that an accurate dose can be administered with ease of administration with increase in residence time of drugs. Srividya, Cardoza, \& Amin prepared a $\mathrm{pH}$-sensitive in-situ ophthalmic gel of ofloxacin hydrochloride using HPMC and carbopol 934 as polymers for treatment of bacterial conjunctivitis (Srividya et al., 2001). Ionactivated in-situ gel forming system of various drugs using Gelrite (gellan gum) as polymer base has also been reported (Balasubramaniam and Pandit, 2003; Sultana et al., 2006). The present study describes the formulation and evaluation of an insitu ocular drug delivery system based on the concept of $\mathrm{pH}-$ and ion-triggered in-situ gelation. Carbopol 940 (pH-sensitive polymer) along with gellan gum (ion-activated gelling polymer) was used as gelling agent.

Dexamethasone sodium phosphate (topical corticosteroid) and Chloramphenicol (antibacterial agent) prescribed in the treatment of ocular endophthalmitis were used in the present study (García-Sáenz et al., 2010).

A 2-factor, 3-level design was used to optimize the formulation parameters and evaluate main and interaction effects of selected independent variables on dependent variables.

\section{MATERIAL AND METHODS}

\section{Materials}

Dexamethasone sodium phosphate (DXM) and Chloramphenicol (CHL) were obtained as gift sample from Priyal pharma Ahmedabad. Gellan gum was obtained as a gift sample from CP Kelco, USA. Carbopol940 purchased from yarrow chem Mumbai. All other chemicals and solvents used of analytical grades purchased from SD fine chem. Mumbai.

\section{Methods}

\section{Formulation of in situ gelling system}

Aqueous solution of different concentration of $\mathrm{pH}$ sensitive carbopol940 and ion sensitive gellan gum were prepared in purified double distilled deionized water by heating at $60-70^{\circ} \mathrm{C}$ with continuous stirring until clear solution was formed. The required quantity of dexamethasone sodium phosphate and chloramphenicol was dissolved in specified amount of propylene glycol. Both the solutions were mixed and required quantity of benzododecinium bromide was added to it. Purified double distilled deionized water was added to make up to the volume 100 $\mathrm{ml}$. The developed formulations were filled in 5-ml capacity amber glass vials, closed with gray butyl rubber closures and sealed with aluminum caps. The formulations, in their final pack, were subjected to terminal sterilization by autoclaving at $121{ }^{\circ} \mathrm{C}$ and 15 psi for $20 \mathrm{~min}$. Mannitol was used as an isotonicity adjusting agent and its quantity in formula was calculated by sodium chloride equivalent method.

\section{Experimental design}

A $3^{2}$ full factorial design was conducted to study the effect of independent variables, concentration of carbopol $940\left(\mathrm{X}_{1}\right)$ and concentration of gellan gum $\left(\mathrm{X}_{2}\right)$, on dependent variables like $\%$ cumulative drug release at $1 \mathrm{hr}\left(\mathrm{Q}_{1}\right)$, time required to release $90 \%$ of the drug $\left(\mathrm{t}_{90 \%}\right)$, mucoadhesive strength, viscosity at both non physiological $\left(25^{\circ} \mathrm{C}, \mathrm{pH} 7.4\right)$ and physiological condition $\left(37^{\circ} \mathrm{C}, \mathrm{pH} 7.4\right)$. The independent and dependent variables are listed in table 1 while all the batches were prepared according to the experimental design shown in table 2 .

Table 1: Selection of independent and dependent variables.

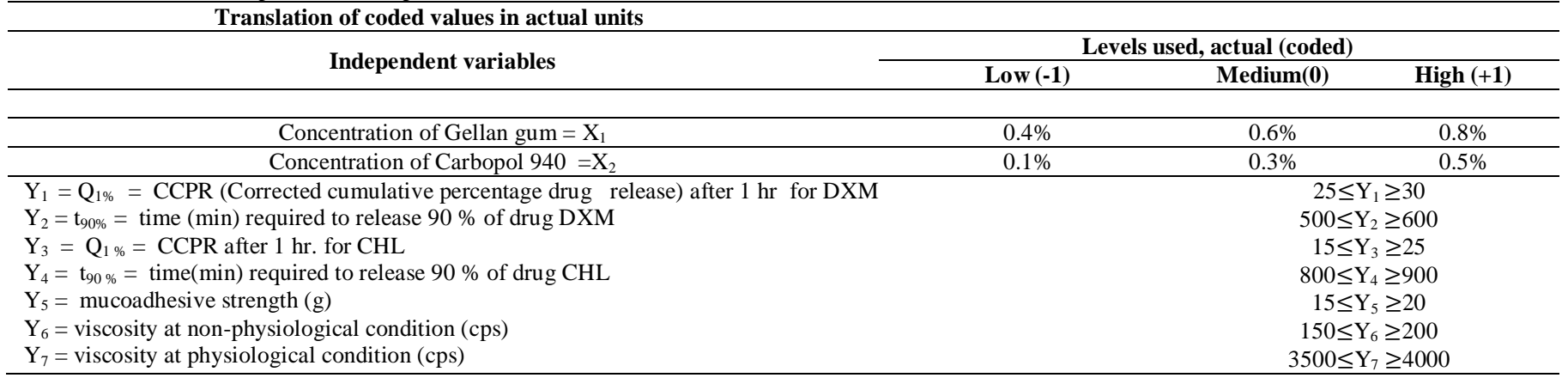


Table 2: The composition of all batches as per $3^{2}$ full factorial design.

\begin{tabular}{|c|c|c|c|c|c|c|c|c|}
\hline Batches & $\begin{array}{c}\text { Dexameth-asone } \\
\text { sodium phosphate }\end{array}$ & $\begin{array}{c}\text { Chloramp- } \\
\text { henicol }\end{array}$ & $\begin{array}{l}\text { Prop-ylene } \\
\text { glycol }\end{array}$ & Mannitol & $\begin{array}{c}\text { Gellan } \\
\text { gum }\end{array}$ & $\begin{array}{c}\text { Carbopol } \\
940 \\
\end{array}$ & $\begin{array}{c}\text { Benzod-odecinium } \\
\text { bromide }\end{array}$ & $\begin{array}{l}\text { Double distilled } \\
\text { deionized water }\end{array}$ \\
\hline F1 & $0.1 \%$ & $0.5 \%$ & $10 \%$ & $4.61 \%$ & $0.4 \%$ & $0.1 \%$ & $0.012 \%$ & q.s to $100 \%$ \\
\hline $\mathrm{F} 2$ & $0.1 \%$ & $0.5 \%$ & $10 \%$ & $4.61 \%$ & $0.4 \%$ & $0.3 \%$ & $0.012 \%$ & q.s to $100 \%$ \\
\hline F3 & $0.1 \%$ & $0.5 \%$ & $10 \%$ & $4.61 \%$ & $0.4 \%$ & $0.5 \%$ & $0.012 \%$ & q.s to $100 \%$ \\
\hline $\mathrm{F} 4$ & $0.1 \%$ & $0.5 \%$ & $10 \%$ & $4.61 \%$ & $0.6 \%$ & $0.1 \%$ & $0.012 \%$ & q.s to $100 \%$ \\
\hline F5 & $0.1 \%$ & $0.5 \%$ & $10 \%$ & $4.61 \%$ & $0.6 \%$ & $0.3 \%$ & $0.012 \%$ & q.s to $100 \%$ \\
\hline F6 & $0.1 \%$ & $0.5 \%$ & $10 \%$ & $4.61 \%$ & $0.6 \%$ & $0.5 \%$ & $0.012 \%$ & q.s to $100 \%$ \\
\hline F7 & $0.1 \%$ & $0.5 \%$ & $10 \%$ & $4.61 \%$ & $0.8 \%$ & $0.1 \%$ & $0.012 \%$ & q.s to $100 \%$ \\
\hline F8 & $0.1 \%$ & $0.5 \%$ & $10 \%$ & $4.61 \%$ & $0.8 \%$ & $0.3 \%$ & $0.012 \%$ & q.s to $100 \%$ \\
\hline F9 & $0.1 \%$ & $0.5 \%$ & $10 \%$ & $4.61 \%$ & $0.8 \%$ & $0.5 \%$ & $0.012 \%$ & q.s to $100 \%$ \\
\hline $\mathrm{F} 10$ & $0.1 \%$ & $0.5 \%$ & $10 \%$ & $4.61 \%$ & $0.6 \%$ & $0.3 \%$ & $0.012 \%$ & q.s to $100 \%$ \\
\hline $\mathrm{F} 11$ & $0.1 \%$ & $0.5 \%$ & $10 \%$ & $4.61 \%$ & $0.6 \%$ & $0.3 \%$ & $0.012 \%$ & q.s to $100 \%$ \\
\hline F12 & $0.1 \%$ & $0.5 \%$ & $10 \%$ & $4.61 \%$ & $0.6 \%$ & $0.3 \%$ & $0.012 \%$ & q.s to $100 \%$ \\
\hline F13 & $0.1 \%$ & $0.5 \%$ & $10 \%$ & $4.61 \%$ & $0.6 \%$ & $0.3 \%$ & $0.012 \%$ & q.s to $100 \%$ \\
\hline
\end{tabular}

(All units are in \% W/V)

\section{Evaluation of in situ gelling system \\ Physicochemical characterization}

The clarity of the formulations after and before gelling was determined by visual examination of the formulations under light alternatively against white and black backgrounds. $\mathrm{pH}$ was checked using digital $\mathrm{pH}$ meter (Janki impex pvt. Ltd.) and viscosity was determined using Brookfield's viscometer (LVDV II+ PRO model) in small volume adapter at $100 \mathrm{rpm}$.

\section{Drug content}

Preparation containing $0.1 \% \mathrm{DXM}$ and $0.5 \% \mathrm{CHL}$ were shaken for few minute and prepared stock solution containing $40 \mu \mathrm{g} / \mathrm{ml} \mathrm{DXM}$ and $200 \mu \mathrm{g} / \mathrm{ml} \mathrm{CHL}$ using simulated tear fluid of pH 7.4 (Balasubramaniam et al., 2003). This stock solution was serially diluted with simulated tear fluid and absorbance was measured at 243 and $278 \mathrm{~nm}$.

\section{In vitro gelling capacity}

The in vitro gelling capacity was determined by placing freshly prepared drop of formulation in a vial containing freshly prepared simulated tear fluid $\left(\mathrm{pH} \mathrm{7.4)}\right.$ and equilibrated at $37^{\circ} \mathrm{C}$. The visual assessment of gel formation was carried out. Time required for gelation as well as time taken for the formed gel to dissolve were also noted. Different grades were allotted with the gel integrity, and rate of formation of gel with respect to time (Patel et al., 2007; Miyazaki et al., 2001; Al-Kassas and El-Khatib MM, 2009). The grades were given as no gelation (-), gelation after 5 minutes and remains for 1-2 $\mathrm{hr}(+)$, gelation immediate and remains for up to $8 \mathrm{hr}(++)$, and gelation immediate and remain extended time $(+++)$.

\section{Viscosity}

The prepared formulations were evaluated for viscosity in order to identify the compositions that best suit for use as in situ gelling systems. The viscosity of the systems was measured using Brookfield viscometer (LV DVII +PRO model) at 100 RPM at non physiological condition and physiological condition (Liu et al., 2010; Le Bourlais et al., 1998).
In vitro drug release study

The In-vitro release studies of DXM and CHL from the formulation were studied through the cellulose acetate membrane (Millipore $0.45 \mu \mathrm{m}$ ) using a modified USP XXIII dissolution apparatus. The dissolution medium used was freshly prepared simulated tear fluid ( $\mathrm{pH}$ 7.4) (Manjappa et al., 2009; Liu et al., 2006; Mansour et al., 2008). A cellulose acetate membrane previously soaked in the dissolution medium was tied to one end of the specifically designed glass cylinder (open at both end of 2.5 $\mathrm{cm}$ diameter). Two $\mathrm{ml}$ of the formulation (equivalent to $2 \mathrm{mg}$ of DXM and $10 \mathrm{mg}$ of CHL) was accurately pipetted into this assembly. The glass cylinder was suspended in $100 \mathrm{ml}$ of dissolution medium at $37 \pm 0.5{ }^{\circ} \mathrm{C}$, so that the membrane just touches the receptor medium surface. A Teflon TM coated magnetic bar continuously stirred the receiving medium at 150 rpm to avoid diffusion layer effects. A formulation sample was placed evenly on the surface of the membrane in the donor compartment. Aliquots, each of $5 \mathrm{ml}$ volume were withdrawn at hourly interval and replaced by an equal volume of dissolution medium to maintain the sink condition. The aliquots were diluted with dissolution medium and analyzed by UV Spectrophotometer at $243 \mathrm{~nm}$ and $278 \mathrm{~nm}$.

To gain a better insight into the mechanisms underlying the release of DXM and CHL from in situ gel forming system and their role in ophthalmic delivery of DXM and CHL, the release kinetics of it were investigated. Dissolution data was given zero order, first order, Higuchi and Korsmeyer kinetic treatment for all the formulations to interpret the release mechanism.

\section{Determination of Mucoadhesive strength and texture analysis Mucoadhesive strength}

A modified balance method was used for determining the mucoadhesive strength. Assembly for measurement of mucoadhesive strength is displayed in figure 1.

The cellophane membrane was cut into pieces previously treated with $0.1 \mathrm{~N} \mathrm{NaOH}$. Two pieces of cellophane membrane were tied to the two wooden pieces separately from that one wooden piece was fixed on the sieve and other piece was tied with 
the balance on right hand side. The right and left wooden were balanced by adding extra weight on the left hand wooden. $1 \mathrm{~g}$ of ophthalmic gel was placed between these wooden pieces containing cellophane membrane, and extra weight from the left pan was removed to sandwich the two pieces of cellophane membrane and some pressure was applied to remove the presence of air.

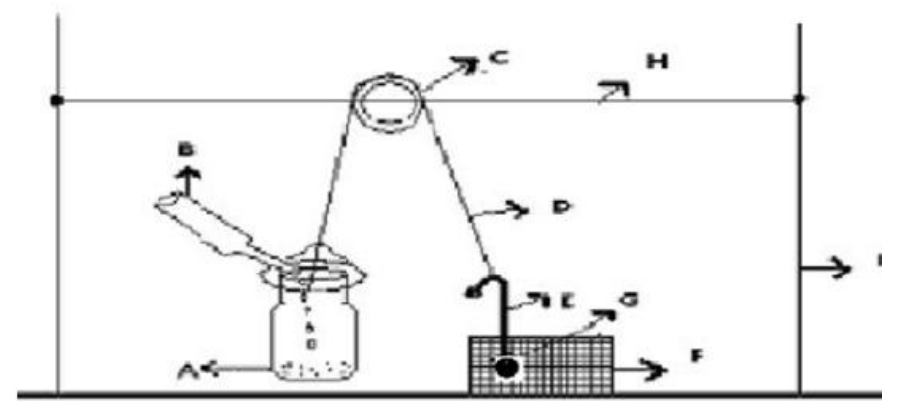

Fig. 1: Assembly for measurement of mucoadhesive strength in which $A=$ Plastic bottle, $\mathrm{B}=$ Pipette, $\mathrm{C}=$ Pulley, $\mathrm{D}=$ Thread, $\mathrm{E}=\mathrm{Pin}, \mathrm{F}=$ Sieve, $\mathrm{G}=$ Wooden pieces, $\mathrm{H}=$ Stainless steel rod, $\mathrm{I}=\mathrm{Stand}$ and $\mathrm{J}=\mathrm{I} n$-situ gel

The balance was kept in this position for 5 minutes. Water was added slowly at $1 \mathrm{ml} / \mathrm{min}$ to the left-hand pan until the gel detached from the cellophane membrane surface. The water $(\mathrm{ml})$ required to detach the gel from the cellophane membrane surface gave the measure of mucoadhesive strength (Patel et al., 2007; Choi et al., 1998; Majithiya et al., 2006; Ch’Ng et al., 1985). The mucoadhesive strength was calculated by using following equations 1 and 2, respectively.

Force of adhesion $(\mathrm{N})=\frac{\text { mucoadhesion strength }(\mathrm{g}) \times 9.81}{1000}---($ Eq. 1)

Bond strength $=\frac{\text { force of adhesion }}{\text { disk surface area }}$

Texture analysis

Texture analysis of optimized gel at physiological condition (STF pH 7.4, $37{ }^{\circ} \mathrm{C}$ ) was carried out by Brookfield QTS Texture Analyzer. Settings used were trigger point of $5 \mathrm{~g}$ and target value of $25 \mathrm{~mm}$ with 1 cycle of $20 \mathrm{~mm} / \mathrm{min}$.

\section{RESULTS AND DISCUSSION}

\section{Evaluation of in situ gelling system Clarity, pH and drug content}

Clarity of the formulations was found to be satisfactory. The formulations were pale yellow in colour. Terminal sterilization with autoclaving had no effect on the physicochemical properties of the formulations. The $\mathrm{pH}$ of all formulations was within the range of 4 to 4.8 and hence would not cause any irritation upon instillation to eye. The drug content was found to be in acceptable range (98-102\%) indicating uniform distribution of drug.

\section{In vitro gelling capacity and viscosity}

The two main prerequisites of an in situ gelling system are viscosity and gelling capacity. The formulation had an optimum viscosity at non physiological conditions (50-160 cps) which would allow easy instillation into the eyes and sudden rise in the viscosity was observed at physiological condition (471-6500 cps) which indicated rapid sol-gel transition at lachrymal $\mathrm{pH}$ (Figure 2). The results of In vitro gelling capacity revealed that gel formed in situ preserved its integrity without dissolving or eroding for a sufficient period of time.

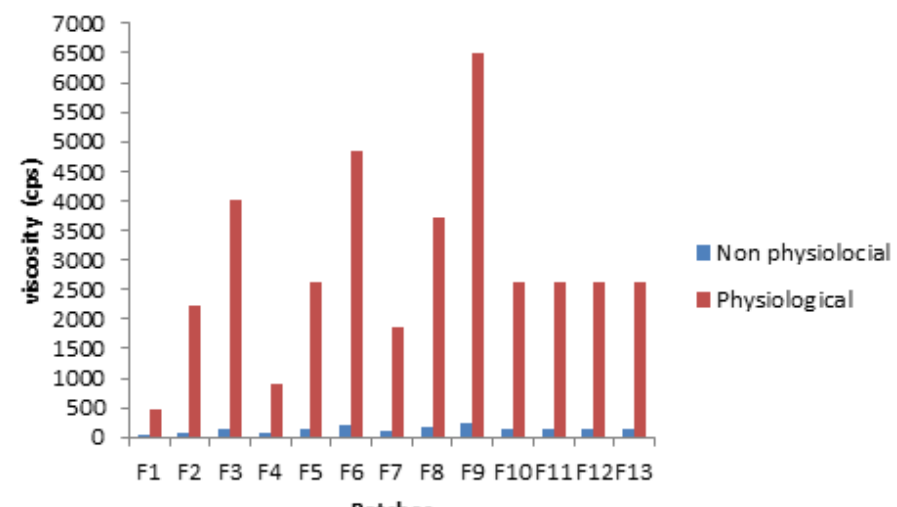

Fig. 2: Viscosity of gel of batches (F1-F13) at non-physiological $\left(25^{\circ} \mathrm{C}\right)$ and at physiological $\left(\mathrm{pH} 7.4\right.$ and $\left.37^{\circ} \mathrm{C}\right)$ conditions

\section{In vitro drug release study}

In-vitro drug release study of all formulations for DXM and CHL is displayed in figure 3 and 4 , respectively.

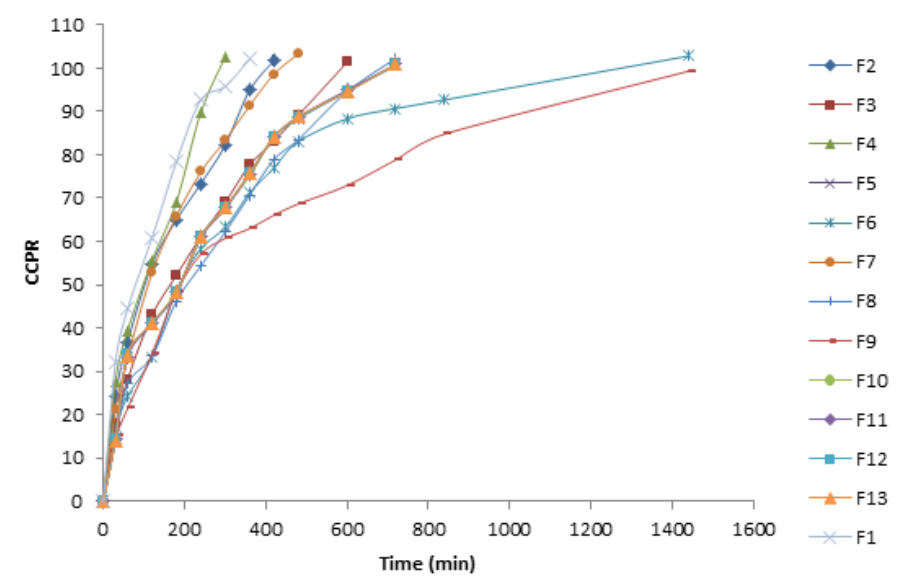

Fig. 3: Comparative In-vitro drug release profile of batches (F1-F13) for DXM

All the solutions contained $0.1 \%$ DXM and $0.5 \%(\mathrm{w} / \mathrm{v})$ CHL. In this work, in situ gel was used as a polymer matrix to control drug release. Increasing the concentration of gellan gum from 0.4 to $0.8 \%$ and the carbopol 940 from 0.1 to $0.5 \%$ has markedly decreased drug release from dosage form. The maximum sustained release effect was associated with F9 formulation and 
minimum sustained release effect was associated with the formulation F1. It is thought that these effects are the function of interaction of two parameters: the polymer type and its concentration. As the polymer concentration increased, the release of DXM and CHL through the formulation reduced due to the more entangled nature of the polymeric network. In addition, the ingress of water into the formulation containing high concentration of polymer was reduced, thus lowering the rates of both dissolution/ erosion. Also, the density of the chain structure of the gels increased at higher polymeric concentrations, and this limits the active substance movement area. Finally, the degree of swelling increased as the concentration of the solids increased thus decreased the diffusion of DXM and CHL from the swollen matrix.

The swelling phenomenon may be directly responsible for the effects of the type of polymer on the drug release from the formulation. In case of F1, F2, F4 and F7 batches, faster and complete release of DXM was achieved within $8 \mathrm{~h}$. This release trend may be attributed to the comparative viscosity and gelling capacity of both formulations at physiological condition. However, slower and complete release of CHL was achieved within $12 \mathrm{hr}$ in all four batches. DXM release was retained up to $10-12 \mathrm{hr}$ and CHL release was retained for more than $12 \mathrm{hr}$ in all the nine batches. The results indicated that the polymer combination approach had better ability to retain the drug. Four batches, F3, F6, F8 and F9, released CHL up to $24 \mathrm{hr}$ whereas; batches F6 and F9 released DXM up to $24 \mathrm{hr}$.

The best release mechanism with higher correlation coefficient $\left(\mathrm{R}^{2}<0.98\right)$ was found with Higuchi's law indicating that the release rate of drug from the swelling matrix gel was proportional to the square root of time.

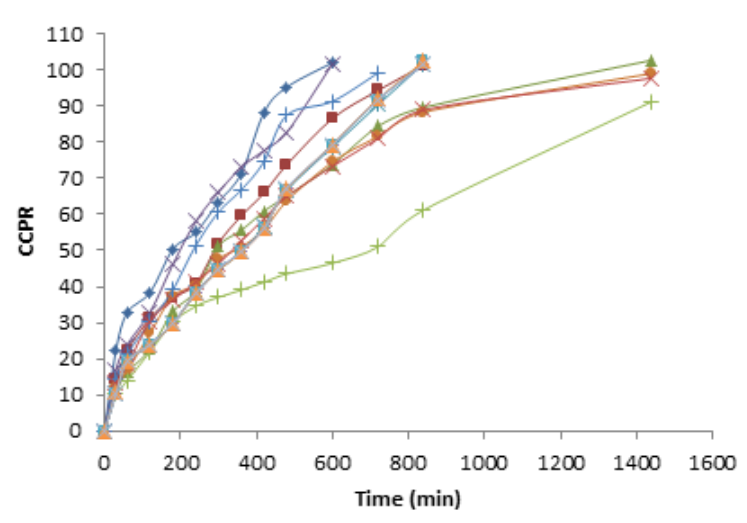

$\rightarrow-F 1$

$\rightarrow-F 2$

$\longrightarrow-\mathrm{F} 3$

$\times$ F4

* F5

$\longrightarrow$ F6

+ 77

$\longrightarrow$ F8

$+\mathrm{Fg}$

$\rightarrow-F 10$

$\rightarrow-F 11$

$\triangle-\mathrm{F} 12$

$\rightarrow-F 13$

Fig. 4: Comparative In-vitro drug release profile of batches (F1-F13) for CHL

\section{Mucoadhesive strength}

Mucoadhesive strength of ophthalmic in situ gel may be due to chemical bonding or it could be because of physical entanglement of swelled polymer with membrane thereby producing stronger mucoadhesion. The mucoadhesive strength of the formulated ophthalmic in situ gel on membrane is due to effect of Carbopol 940 and gellan gum. The data for mucoadhesive strength for all the batches are displayed in figure 5 .

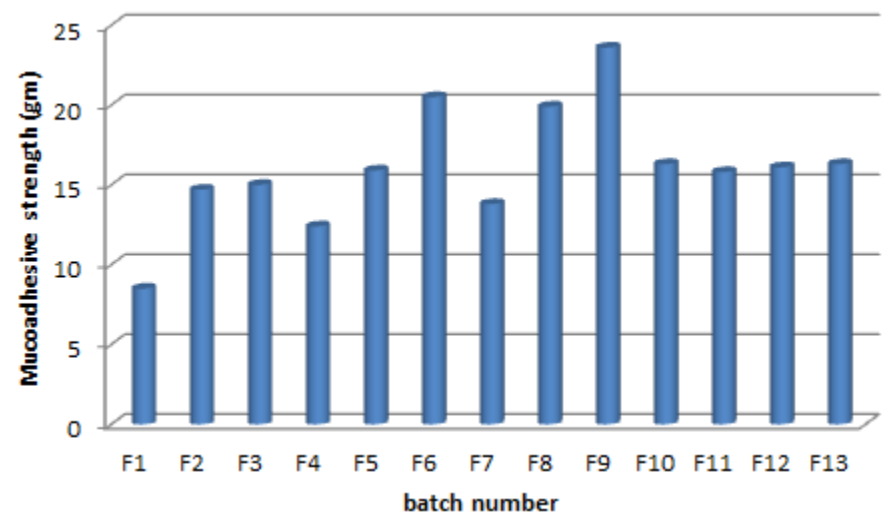

Fig. 5: Mucoadhesive strength of batches (F1-F13) at physiological ( $\mathrm{pH} 7.4$ and $37^{\circ} \mathrm{C}$ ) conditions

The range for mucoadhesive strength of batch F1- F13 was found to be $8.5 \pm 0.71$ to $23.6 \pm 0.43$. The results show that if Carbopol 940 concentration is increased up to $0.5 \%$, sudden rise in mucoadhesive strength. The combination of Carbopol 940 and Gellan gum provides high polymer entanglement and complexation.

These results indicate that both Carbopol 940 and gellan gum played an important role in the matrix mucoadhesion. It is known that this phenomenon is a consequence of several steps such as polymer hydration, mucosa wetting, and interpenetration of the mucoadhesive polymer with the mucus gel. Due to its swelling properties, Carbopol 940 provides a large adhesive surface for maximum contact with mucosa, absorbing moisture from the mucosal surface and thus permitting interpenetration of the polymer into the mucosal layer and subsequent hydrogen bonding.

\section{Statistical Analysis}

A two-factor, three-level full factorial statistical experimental design as the Response Surface Methodology (RSM) requires 13 experiments. All the responses observed for 13 formulations prepared were simultaneously fit to quadratic model using Design Expert 8.0.7.1.It was observed that the best fit model was quadratic model. A positive value of coefficient represents an effect that favors the optimization, while a negative value of coefficient indicates an inverse relationship between the factor and the response.

Statistical validation of the polynomial equations generated by Design Expert was established on the basis of ANOVA provision in the Design Expert software. A total of 13 runs with four center points were generated. The models were evaluated in terms of statistically significant coefficients and $\mathrm{R}^{2}$ values. The statistical analysis of the factorial design batches was also verified by multiple linear regression analysis using Microsoft Excel and response surface plots were generated using Design 
expert software (Version 8.0.7.1). These also suggest that selected independent variable significantly affected responses/independent variables. It can be also be concluded that model of each response has good $\mathrm{R}^{2}$ values (>0.91) indicating that variation in dependent variables are explained by selected independent variables. This would also play an important role in prediction of responses to formulate an ideal ocular in situ gelling system.

\section{Data analysis of $Y_{1}\left(Q_{1 \%} D X M\right)$ and $Y_{3}\left(Q_{1 \%} C H L\right)$}

The observed value for $\mathrm{Q}_{1 \%} \mathrm{DXM}$ and $\mathrm{Q}_{1 \%} \mathrm{CHL}$ for all 13 batches (F1-F13) varied from $21.7 \%$ to $44.3 \%$ and from $14.6 \%$ to $32.6 \%$, respectively. The result clearly indicated that $Y_{1}$ and $Y_{3}$ were strongly affected by the independent variables selected for the study. $Y_{1}$ and $Y_{3}$ obtained at various levels of two independent variables were subjected to multiple regressions to give quadratic polynomial equations no. 1 and 2, respectively.

$\mathrm{Y}_{1}=33.33-7.0 \mathrm{X}_{1}-4.58 \mathrm{X}_{2}+1.15 \mathrm{X}_{1} \mathrm{X}_{2}-0.96 \mathrm{X}_{1} 2-0.71 \mathrm{X}_{2} 2-\mathrm{Eq} 1$

$\left(\mathrm{F}\right.$ value $=151.98, \mathrm{P}$ value $=<0.0001$ and $\mathrm{R}^{2}$ value $\left.=0.9909\right)$

$\mathrm{Y}_{3}=19.47-5.12 \mathrm{X}_{1}-2.90 \mathrm{X}_{2}+2.43 \mathrm{X}_{1} \mathrm{X}_{2}+0.91 \mathrm{X}_{1}^{2}+0.96 \mathrm{X}_{2}^{2}$ Eq. 2

$\left(\mathrm{F}\right.$ value $=45.6, \mathrm{P}$ value $=<0.0001$ and $\mathrm{R}^{2}$ value $\left.=0.9703\right)$

Both independent variables, $X_{1}$ and $X_{2}$, had negative value indicating unfavorable effect on $\mathrm{Y}_{1}\left(\mathrm{Q}_{1 \%} \mathrm{DXM}\right)$ and $\mathrm{Y}_{3}\left(\mathrm{Q}_{1 \%}\right.$ CHL).As per coefficient values, $\mathrm{X}_{1}$ had prominent effect compare to $\mathrm{X} 2$. The variable $\mathrm{X}_{1}$ and $\mathrm{X}_{2}$ were also found to be significant $(\mathrm{P}<0.05)$.

\section{Data analysis of $Y_{2}\left(t_{90 \%} D X M\right)$ and $Y_{4}\left(t_{90 \%} C H L\right)$}

The observed value for $\mathrm{t}_{90 \%} \mathrm{DXM}$ and $\mathrm{t}_{90 \%} \mathrm{CHL}$ for all 13 batches F1-F13 varied from 228 to $972 \mathrm{~min}$ and 486 to $1362 \mathrm{~min}$, respectively. The results clearly indicate that responses, $\mathrm{Y}_{2}$ and $\mathrm{Y}_{4}$, were strongly affected by the independent variables selected for the study. The responses $\mathrm{Y}_{2}$ and $\mathrm{Y}_{4}$ obtained at various levels of three independent variables were subjected to multiple regression to give a quadratic polynomial equation no. 3 and 4, respectively.

$\mathrm{Y}_{2}=478.97+236.0 \mathrm{X}_{1}+123.0 \mathrm{X}_{2}+84.0 \mathrm{X}_{1} \mathrm{X}_{2}+36.32 \mathrm{X}_{1}^{2}-14.38 \mathrm{X}_{2}^{2} \mathrm{Eq} \cdot 3$

$\left(\mathrm{F}\right.$ value $=76.53, \mathrm{P}$ value $=<0.0001$ and $\mathrm{R}^{2}$ value $\left.=0.9820\right)$

$\mathrm{Y}_{4}=708.21+284.0 \mathrm{X}_{1}+123.0 \mathrm{X}_{2}+88.5 \mathrm{X}_{1} \mathrm{X}_{2}+62.28 \mathrm{X}_{1}^{2}+71.28 \mathrm{X}_{2}^{2} \mathrm{Eq} .4$

$\left(\mathrm{F}\right.$ value $=118, \mathrm{P}$ value $=<0.0001$ and $\mathrm{R}^{2}$ value $\left.=0.9883\right)$

Out of two independent variables, both $X_{1}$ and $X_{2}$ have positive value of co-efficient suggesting favorable effect on $190 \%$. The variable $\mathrm{X}_{1}$ and $\mathrm{X}_{2}$ significantly $(\mathrm{P}<0.0001)$ affect in sustaining the drug release. The variable $X_{1}$ has almost two fold effects on $\mathrm{Y}_{2}$ compared to variable $\mathrm{X}_{2}$ which is indicate the gellan gum have superior effect than carbopol in sustaining the drug release.

\section{Data analysis of $Y_{5}$ (mucoadhesive strength)}

The observed value for Mucoadhesive strength for all 13 batches F1-F13 varied from 8.5 to $23.7 \mathrm{~g}$. The batches F6 and F9 had the higher value of Mucoadhesive strength $(>20 \mathrm{~g})$. The response $\left(Y_{5}\right)$ obtained at various levels of three independent variables were subjected to multiple regression to give a quadratic polynomial equation no. 5

$\mathrm{Y}_{5}=16.12+4.18 \mathrm{X}_{1}+3.10 \mathrm{X}_{2}+0.70 \mathrm{X}_{1} \mathrm{X}_{2}-0.040 \mathrm{X}_{1}^{2}+0.29 \mathrm{X}_{2}^{2} \mathrm{Eq} .5$

$\left(\mathrm{F}\right.$ value $=40.93, \mathrm{P}$ value $=<0.0001$ and $\mathrm{R}^{2}$ value $\left.=0.9669\right)$

Out of two independent variables, $\mathrm{X}_{1}$ and $\mathrm{X}_{2}$ has positive value of co-efficient (4.18 and 3.10 respectively) indicating favorable effect on $Y_{5}$. These variables were also found to be significant $(\mathrm{P}<0.0001)$ indicating a major contributing effect of $\mathrm{X}_{1}$ and $\mathrm{X}_{2}$ on $\mathrm{Y}_{5}$. The effect of gellan gum on mucoadhesive strength was higher than the carbopol. The interaction between variable $\mathrm{X}_{1}$ and $X_{2}$ had a positive value of co-efficient and also significant $(\mathrm{P}<0.0001)$ in making effect on $\mathrm{Y}_{5}$. This indicates that combination of Carbopol 940 and gellan gum will have synergistic effect on $\mathrm{Y}_{5}$.

\section{Data analysis of $Y_{6}$ (viscosity at non-physiological condition) and $Y_{7}$ (viscosity (cps) at physiological condition)}

The observed value for $\mathrm{Y}_{6}$ and $\mathrm{Y}_{7}$ for all 13 batches F1F13 varied from 471.7 to $6500 \mathrm{Cp}$ and 471.7 to $6500 \mathrm{Cp}$, respectively. Batches F3, F5, F6, F8 and F9 had the highest viscosity at physiological condition (>2600 cps). Quadratic polynomial equation for response $Y_{6}$ and response $Y_{7}$ are given in equation no. 6 and 7 , respectively.

$$
\begin{aligned}
& \mathrm{Y}_{6}=136.22+58.53 \mathrm{X}_{1}+48.53 \mathrm{X}_{2}+4.45 \mathrm{X}_{1} \mathrm{X}_{2}-0.33 \mathrm{X}_{1}^{2}+3.37 \mathrm{X}_{2}^{2} \mathrm{Eq} .6 \\
& \left(\mathrm{~F} \text { value }=2288.04, \mathrm{P} \text { value }=<0.0001, \mathrm{R}^{2} \text { value }=0.9994\right) \\
& \mathrm{Y}_{7}=2632.7+2025.22 \mathrm{X} 1+889.88 \mathrm{X} 2+270.67 \mathrm{X} 1 \mathrm{X} 2+242.05 \mathrm{X} 12 \\
& +341.05 \mathrm{X} 22---\mathrm{Eq} .7 \\
& \left(\mathrm{~F} \text { value }=571.40, \mathrm{P} \text { value }=<0.0001, \mathrm{R}^{2} \text { value }=0.9976\right)
\end{aligned}
$$

The above equation clearly reflects the wide range of values of various co-efficient (b). Out of two independent variables, $\mathrm{X} 2$ has lower value of co-efficient (889.88). The coefficient value for $X_{1}$ and $X_{2}$ is 2025.22 and 889.88 respectively and these two variable were also found to be significant $(\mathrm{P}<0.0001)$. This indicated a major contributing effect of $\mathrm{X}_{1}$ and $\mathrm{X}_{2}$ on $\mathrm{Y}_{7}$. Hence the effect of variable $\mathrm{X}_{1}$ and $\mathrm{X}_{2}$ on consistency or gelling property is equivalent on viscosity at physiological condition $\left(\mathrm{Y}_{7}\right)$. Gellan gum and carbopol can be use to improve the consistency of the formulations and also achieve sol to gel transition at physiological condition.

\section{Contour plots and response surface analysis}

The plots obtained from design expert software clearly show that there is non-linear relationship between independent $\left(X_{1}\right.$ and $\left.\mathrm{X}_{2}\right)$ and dependent variables $\left(\mathrm{Y}_{1}-\mathrm{Y}_{7}\right)$.

\section{Optimization of formulation}

Based on the inferences derived from Design Expert, optimized formulation consisted of $0.1 \%$ Dexamethasone sodium phosphate, $0.5 \%$ Chloramphenicol, 10\% Propylene glycol, $0.58 \%$ Gellan gum, $0.40 \%$ Carbopol 940, $0.012 \%$ Benzododecinium 
bromide and Double distilled deionized water upto $100 \%$. Results of responses $\left(\mathrm{Y}_{1}-\mathrm{Y}_{7}\right)$ for optimized batch are reported in table 3.

Table 3 Results of optimized batch for response variables.

\begin{tabular}{|c|c|c|c|}
\hline Response variables & Constrains & 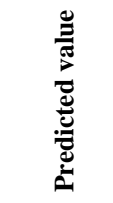 & 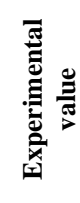 \\
\hline $\mathrm{Y}_{1}=\mathrm{Q}_{1 \%}(\mathrm{DXM})$ & $25 \leq Y_{1} \geq 30$ & 29.98 & 27.10 \\
\hline $\mathrm{Y}_{2}=\mathrm{t}_{90 \%}(\mathrm{DXM})$ & $500 \leq \mathrm{Y}_{2} \geq 600$ & 589.42 & 530.0 \\
\hline $\mathrm{Y}_{3}=\mathrm{Q}_{1 \%}(\mathrm{CHL})$ & $15 \leq \mathrm{Y}_{3} \geq 25$ & 17.31 & 17.01 \\
\hline $\mathrm{Y}_{4}=\mathrm{t}_{90 \%}(\mathrm{CHL})$ & $800 \leq Y_{4} \geq 900$ & 849.72 & 850.0 \\
\hline $\mathrm{Y}_{5}=$ Mucoadhesive strength $(\mathrm{g})$ & $15 \leq Y_{5} \geq 20$ & 17.72 & 19.1 \\
\hline $\begin{array}{l}Y_{6}=V i s c o s i t y \text { at non- } \\
\text { physiological condition }(\mathrm{cps})\end{array}$ & $150 \leq Y_{6} \geq 200$ & 160.35 & 163.5 \\
\hline $\begin{array}{l}Y_{7}=\text { Viscosity at physiological } \\
\text { condition }(\mathrm{cps})\end{array}$ & $3500 \leq Y_{7} \geq 4000$ & 3606.43 & 4013 \\
\hline
\end{tabular}

\section{Texture analysis}

The maximum force represents as a peak on the figure 6(a) measures firmness of gel. $51018 \mathrm{~g}$ force was required to break the gel which indicated high strength of the gel. The area under the positive part of graph indicates sample consistency (work done to hardness); the higher the value (64617.83 g) the thicker and higher the consistency of the sample.
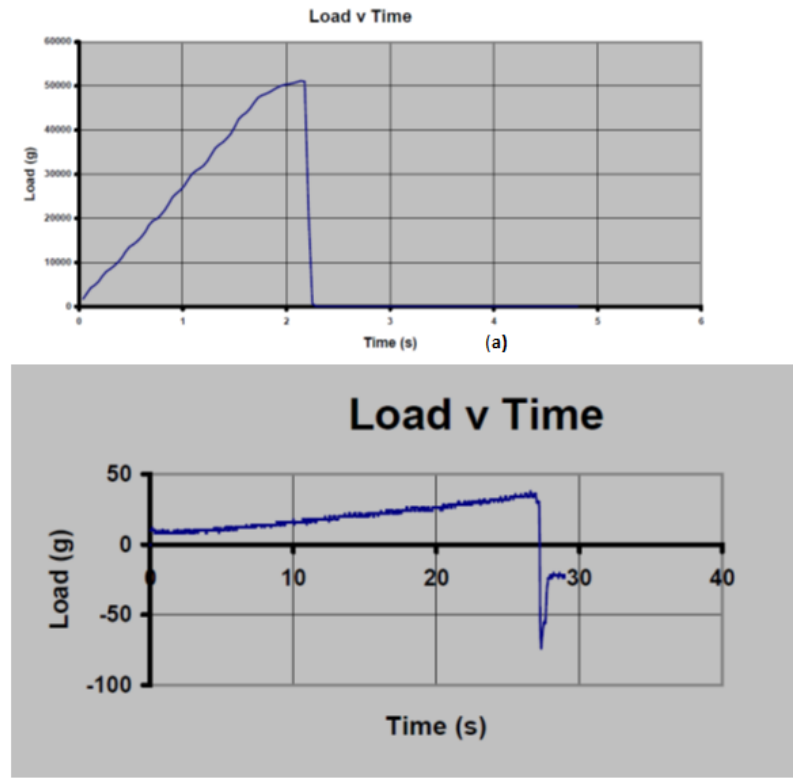

(b)

Fig. 6: Results of (a) gel strength and gel rupture and (b) Mucoadhesion strength by texture analysis.

As probe returns to its starting position, the initial lifting of the weight of the sample on the upper surface of the disk produces the negative part $(-57.22 \mathrm{~g})$ resulting from back extrusion. (Figure 6(b)). This gives an indication of cohesiveness and resistance of the sample to separate (flow off) the disk. The maximum negative force on the graph (-74.0 g) indicates sample adhesive force; the more negative the value, the more sticky the sample.

\section{Validation of RSM}

Table 4 shows the composition of check-point formulations, their predicted and experimental values for all the response variables, and the percentage error in prognosis. All the dependent variables $\left(\mathrm{Y}_{1}-\mathrm{Y}_{7}\right)$ were found to be within limits. For validation of RSM results, the experimental values of the responses were compared with the anticipated values and the prediction error was found to vary between -13.49 and 14.76. The linear correlation plots drawn between the predicted and experimental values demonstrated high values of $\mathrm{R}^{2}$ indicating excellent goodness of fit. Thus the low magnitudes of error as well as the significant values of $\mathrm{R}^{2}$ in the present investigation prove the high prognostic ability of the RSM.

Table 4 Composition of checkpoint formulations, the predicted and experimental values of response variables and \% prediction error.

\begin{tabular}{ccccc}
\hline $\begin{array}{c}\text { Checkpoint } \\
\text { formulation } \\
\text { composition } \\
(\mathbf{X 1 : X 2 )}\end{array}$ & $\begin{array}{c}\text { Response } \\
\text { variable }\end{array}$ & $\begin{array}{c}\text { Experimental } \\
\text { value }\end{array}$ & $\begin{array}{c}\text { Predicted } \\
\text { value }\end{array}$ & $\begin{array}{c}\% \\
\text { prediction } \\
\text { error }\end{array}$ \\
\hline & $\mathrm{Y}_{1}$ & 43.6 & 41.99 & 3.83 \\
& $\mathrm{Y}_{2}$ & 298 & 326.03 & -8.59 \\
$0.2: 0.5$ & $\mathrm{Y}_{3}$ & 25.8 & 24.55 & 5.09 \\
$(-0.5:-0.5)$ & $\mathrm{Y}_{4}$ & 624 & 560.22 & 11.38 \\
& $\mathrm{Y}_{5}$ & 11.8 & 12.6 & -6.34 \\
& $\mathrm{Y}_{6}$ & 96.2 & 84.54 & 13.79 \\
& $\mathrm{Y}_{7}$ & 366.7 & 423.91 & -13.49 \\
\hline & $\mathrm{Y}_{1}$ & 29.4 & 27.41 & 7.26 \\
& $\mathrm{Y}_{2}$ & 624 & 685.03 & -8.90 \\
$0.4: 0.7$ & $\mathrm{Y}_{3}$ & 16.1 & 16.53 & -2.60 \\
$(+0.5:+0.5)$ & $\mathrm{Y}_{4}$ & 1110 & 967.22 & 14.76 \\
& $\mathrm{Y}_{5}$ & 19.05 & 19.86 & -4.07 \\
& $\mathrm{Y}_{6}$ & 215.2 & 191.6 & 12.31 \\
& $\mathrm{Y}_{7}$ & 4251 & 4303.6 & -1.22 \\
\hline
\end{tabular}

\section{Stability study}

The optimized formulation was found to be clear after one months of storage at $40^{\circ} \mathrm{C}$ and $75 \% \mathrm{RH}$ and no change in drug content and viscosity at non physiological condition (100 RPM) was observed.

\section{CONCLUSION}

In situ gel forming eye drops using gellan gum and carbopol 940 was successfully formulated for dexamethasone sodium phosphate and chloramphenicol used in the treatment of endophthalmitis. The formulation was optimized using two-factor, three level $3^{2}$ full factorial experimental design. The amount of independent variables carbopol $940\left(\mathrm{X}_{1}\right)$ and gellan gum $\left(\mathrm{X}_{2}\right)$ showed a significant effect on the dependent variables $\left(\mathrm{Y}_{1}-\mathrm{Y}_{7}\right)$. The quantitative effect of these factors at different levels was predicted using quadratic polynomial equations. Response surface methodology was used to predict the levels of the factors $X_{1}$ and $\mathrm{X}_{2}$ required to obtain optimum formulation with desired $\mathrm{Q}_{1 \mathrm{hr}}, \mathrm{t}_{90 \%}$, mucoadhesive strength and viscosity at non-physiological and 
physiological condition. An optimized formulation was prepared according to which it afforded sustain release of drugs over 10-12 hr periods. Observed responses were in close agreement with the predicted values of the optimized formulation, thereby demonstrating the feasibility of the optimization procedure in developing sustain release in situ ophthalmic gel for ocular drug delivery. Stability study of the optimized formulation proved the integrity of the developed in situ gel. It was also concluded that carbopol 940 and gellan gum can be used together as in situ gelling vehicle to enhance the patient compliance. IT was also concluded that $3^{2}$ full-factorial experimental design facilitated the optimization of ocular in situ gel to obtain desired responses necessary for ideal sustained ocular delivery of combination of two drugs. The developed stable formulation could be a viable alternative to conventional eye drops for treatment of endophtalmitis.

\section{ACKNOWLEDGMENTS}

Authors are thankful to Priyal Pharma, Ahmedabad for providing gift sample of active pharmaceutical ingredients. Authors are also thankful to Dr. D. R. Shah (Provost Uka Tarsadia University, Surat) and Dr. S. A. Shah (Principal, Maliba Pharmacy College, Surat) for providing necessary facilities to carry out research.

Conflict of Interests: There are no conflicts of interest.

\section{REFERENCES}

Al-Kassas RS, El-Khatib MM. Opthalmic controlled release in situ gelling system for ciprofloxacin based on polymeric carriers. Drug Deliv, 2009; 16: 145-152.

Balasubramaniam J, Kant S, Pandit JK. In vitro and in vivo evaluation of gelrite gellan gum based ocular delivery system for indomethacin. Acta. Pharma, 2003; 53: 251-262.

Balasubramaniam J, Pandit J. Ion-Activated in Situ Gelling Systems for Sustained Ophthalmic Delivery of Ciprofloxacin Hydrochloride. Drug Deliv, 2003; 10: 185-191.

Ch'Ng HS, Park H, Kelly P, Robinson JR. Bioadhesive polymers as platforms for oral controlled drug delivery II: Synthesis and evaluation of some swelling, water insoluble bioadhesive polymers. J Pharm Sci, 1985; 74: 399-405.

Choi HG, Jung JH, Ryu JM, Yoon SJ, Oh YK, Kim CK. Development of in situ-gelling and mucoadhesive acetaminophen liquid suppository. Int J Pharm, 1998; 165: 33-44.

García-Sáenz M, Arias-Puente A, Rodríguez-Caravaca G, Andrés Alba Y, Bañuelos Bañuelos J. Endophthalmitis after Cataract Surgery: Epidemiology, Clinical Features and Antibiotic Prophylaxis. Archives of the Spanish Ophthalmology Society, 2010; 85: 263-267.
Gupta H, Jain S, Mathur R, Mishra P, Mishra AK, Velpandian T. Sustained Ocular Drug Delivery from a Temperature and $\mathrm{Ph}$ Triggered Novel in Situ Gel System. Drug Deliv, 2007; 14: 507-515.

Gupta H, Velpandian T, Jain S. Ion-and pH-Activated Novel inSitu Gel System for Sustained Ocular Drug Delivery. J drug Target, 2010; 18: 499-505.

Le Bourlais C, Acar L, Zia H, Sado PA, Needham T, Leverge R. Opthalmic drug delivery systems-recent advances. Prog Retinal. Eye Res, 1998; 17: 33-58.

Liu Z, Li J, Nie S, Liu H, Ding P, Pan W. Study of an alginate/HPMC-based in situ gelling ophthalmic delivery system for gatifloxacin, Int J Pharm, 2006; 315: 12-17.

Liu Y, Liu J, Zhang X, Zhang R, Huang Y, Wu C. In situ Gelling Gelrite/Alginate Formulation as Vehicles for Opthalmic Drug Deliery. AAPS PharmSciTech, 2010; 11: 610-620.

Majithiya RJ, Ghosh PK, Umrethia MK, Murthy RSR. Thermoreversible-mucoadhesive gel for nasal delivery of sumatriptan. AAPS PharmSciTech, 2006; 74: 80-86.

Manjappa A, Nanjwade BK, Manvi F, Murthy R. Sustained Ophthalmic in Situ Gel of Ketorolac Tromethamine: Rheology and in Vivo Studies. Drug Develop Res, 2009; 70: 417-424.

Mansour M, Mansour S, Mortada ND, Abd ElHady SS. Ocular poloxamer-based ciprofloxacin hydrochloride in situ forming gels. Drug Dev Ind Pharm, 2008; 34: 744-752.

Maurice D, Mishima S.1984. Pharmacology of the Eye. Verlag Berlin Heidelberg: Springer.

Miyazaki S, Suzuki S, Endo K, Takahashi A, Attwood D. In situ gelling xyloglucan formulation for sustained release ocular delivery of pilocarpine hydrochloride. Int J Pharma, 2001; 229: 29-36.

Pal Kaur I, Kanwar M. Ocular Preparations: The Formulation Approach. Drug Dev Ind Pharm 2002; 28: 473-493.

Patel VM, Prajapati BG, Patel MM. Design and characterization of chitosan containing mucoadhesivebuccal patches of propranolol hydrochloride. Acta Pharm, 2007; 57: 61-72.

Srividya B, Cardoza RM, Amin P. Sustained Ophthalmic Delivery of Ofloxacin from a $\mathrm{pH}$ Triggered in Situ Gelling System. J control Release, 2001; 73: 205-211.

Sultana Y, Aqil M, Ali A. Ion-Activated, Gelrite ${ }^{\circledR}$-Based in Situ Ophthalmic Gels of Pefloxacin Mesylate: Comparison with Conventional Eye Drops. Drug Deliv, 2006; 13: 215-219.

\section{How to cite this article:}

Ranch K, Patel H, Chavda L, Koli A, Maulvi F, Parikh RK. Development of in situ Ophthalmic gel of Dexamethasone Sodium Phosphate and Chloramphenicol: A Viable Alternative to Conventional Eye Drops. J App Pharm Sci, 2017; 7 (03): 101-108. 